\title{
Socioeconomic and Institutional Factors Determining the Utiliza- tion of Fish Resource in Lake Ziway
}

\author{
Esayas Hailu1, Yemiru Tesfaye2, Yosef Teklegiorgis3, Solomon Tsegaye4* \\ ${ }^{1}$ Alage ATVET College, Department of Natural Resourse, Ziway-Alage, Ethiopia \\ ${ }^{2}$ Hawassa University, Wondo Genet College of Forestry and Natural resources, Department of Forestry, Wondo \\ Genet, Ethiopia \\ ${ }^{3}$ Hawassa University, College of Agriculture, Department of Animal Science, Hawassa, Ethiopia \\ ${ }^{4}$ Woldia University, College of Agriculture, Department of Animal Production and Technology, Woldia, Ethiopia
}

"Corresponding author: Solomon Tsegaye, Woldia University, College of Agriculture, Department of Animal Production and Technology, Woldia, Ethiopia. Tel: +251913733048; E-Mail: solomontsegaye25@gmail.com

Citation: Hailu E, Tesfaye Y, Teklegiorgis Y, Tsegaye S (2017) Socioeconomic and Institutional Factors Determining the Utilization of Fish Resource in Lake Ziway. J Fish Aquac Dev 2017: JFAD-109. DOI:10.29011/JFAD-109/100009

Received Date: 3 May 2017; Accepted Date: 17 May, 2017; Published Date: 27 May, 2017

\begin{abstract}
Lake Ziway is the most exploited lake for fishery, irrigation, recreation and tourism, the fishery sustainability of which is reported under threat because of the overfishing activity resulting from an increasing number of fishers residing around the lake. The main concern of this study was, therefore, to analyze the major socio-economic and institutional factors that determine people's decision to be engaged in fishing activities there by contributing to the over utilization of the fish resource in Lake Ziway. The study was based on the data obtained from randomly selected 120 households in four Peasant Associations (PAs) purposely selected from two districts. Binary logistic regression analysis was used to identify socioeconomic and institutional factors that determine the utilization of fish resource in the lake. Eight explanatory variables were included in the model out of which five were found to be significant. Results of the logistic regression analysis indicated that age, educational level, distance of household's home from the lake and other income generating activities determine fish resource utilization negatively while credit access was found to have a positive impact. In the analysis of the relative importance of the significant variables it was found that a one year increase in the age of an average household will decrease the probability of his engagement in fishing activities by $1.6 \%$ and a $1 \mathrm{~km}$ increase in the distance of the household's residence from the lake to decrease the probability of engagement in fishing activity by $8.7 \%$. Furthermore, the probability of being fisherman increases for a person with the education level of reading and writing by $30.4 \%$ as compared to a household with a higher education while the probability for a household who does not have other source of income increases by $42 \%$; and it increases for the one who has credit access by $26 \%$. The finding of the study suggests that, improving the educational level and facilitating diversified income generating opportunities for the households living around the lake would help to mitigate the overutilization.
\end{abstract}

Keywords: Fish; Institutional Arrangement; Lake Ziway; Overfishing Activity, Socioeconomic

\section{Introduction}

Ethiopia, the second-most populous country in Sub-Saharan Africa with a population of 96.5 million [1] and with a population growth rate of $2.5 \%$ in 2014, has an agrarian dominated economy with the agricultural sector accounting for $85 \%$ of the total em- ployment, $98 \%$ of the total calorie supply, $70 \%$ of industrial raw material supplies, over $45 \%$ of GDP and $90 \%$ of the foreign currency earning [2]. Ethiopia is with the largest livestock populations in the Africa, where the sector accounts for over $26 \%$ of agricultural GDP (2009/10) and $8 \%$ of export earnings in 2010 and can produce over 51,500 $t$ of fish per annum [2]. However, in spite of the availability of technological capability to resolve the problems of livestock and fisheries production their exploitation 


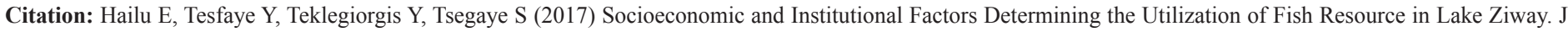
Fish Aquac Dev 2017: JFAD-109.

and consequently their contributions to food security and growth in the country are minimal.

Artisanal freshwater fishery being one of the most important economic activities in Ethiopia, improvements in fishery sector can potentially contribute to poverty alleviation and environmental sustainability in the country. Lake Ziway being one of the Lakes in the country with substantial fish resource and fishery activity it is an important commercial center as a major supplier of fish to the markets in Addis Ababa [3]. It is one of the fresh water lakes, having a low salt concentration. The total dissolved solids in the lake range between 200 and $400 \mathrm{mg} / \mathrm{l}$, having a pH of neutral to slightly alkaline [4]. The potential fish yield of Lake Ziway is estimated at about $15 \%$ of the total potential of the country's major lakes while it contributes about $24 \%$ of the current yield from all the major lakes in the country. Compared to the biggest lake in the country, Lake Ziway produces twice as much yield and its socio-economic importance to the local community is also found to be high.

Fishery collapse is a consequence of overfishing which usually comes before severe stock depletion. Continuous exertion of fishing pressure in spite of decline in production leads to a collapse in the stock and the failures in fishery are primarily the product of institutional failure. Today over $70 \%$ of fish species are fully exploited, overexploited, depleted, or recovering from depletion. Lack of well-defined property rights can have a variety of harmful effects on a fishery, one common repercussion being the presence of excessive fishing beyond the maximum capacity [5].

In this regard, Lake Ziway is the most exploited lake for fishery, irrigation and recreation and tourism. Fishery sustainability of this lake is reported to be under threat because of fishing pressure among others [6]. Of the various reasons for the fish population in Lake Ziway to continually deplete, the most important one is the overfishing activity due to an increase in the number of fishers residing around the lake. Secondary data shows that total fish landing from the lake is declining and fish species composition of the lake is also changing, threatening the fishery's sustainability.

The overall objective of the study was to analyze the major socio-economic and institutional factors that determine people's decision to be engaged in fishing activities there by contributing to the extent of utilization of the fish resource in Lake Ziway.

\section{Material and Methods}

Study Area: Lake Ziway, located in the sub-tropical (monsoon) agro-climatic zone (Lat.: 7052'-808' N; Long.: 38040'$38056^{\prime}$ E) is the most northern lake in the closed Ziway-Shala basin in the central rift valley region of Ethiopia. It has an area of $434 \mathrm{~km} 2$, a maximum depth of $7 \mathrm{~m}$ and a mean depth of 2.5 $\mathrm{m}$. It is located at an altitude of $1636 \mathrm{~m}$ and about $160 \mathrm{~km}$ south of the capital city of Addis Ababa. It is found in the National Regional State of Oromia. The lake is bordered by three districts, in
South-East direction by Ziway Dugda District, Arsi Zonal Administration, in West by AdamiTullu-Jiddo-Kombolcha District and in North-West direction by Dugda Bora District, in which the latter both districts are selected as study areas and found in East-Shoa Zonal Administration (Figure1). The economic importance of the lake is high as it is easily accessible and situated near the main asphalted highway, which is extended from the southern part of the country to Addis Ababa market outlets [7].

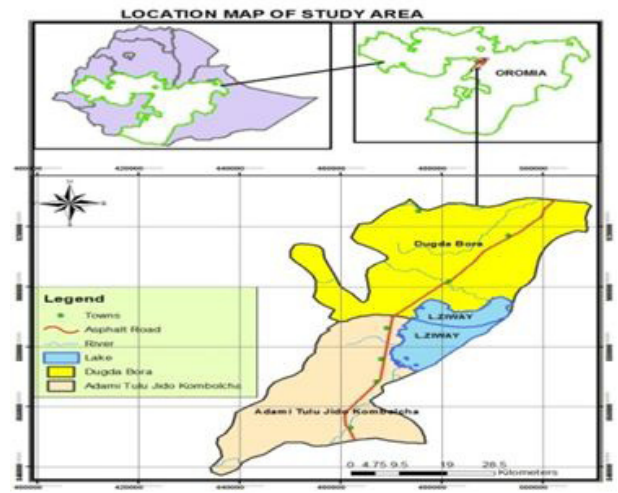

Figure 1: Geographical Location of the Study Area.

Sampling Procedure and Sample Size Determination: Multi stage sampling procedure was employed for the selection of sample respondents. The study districts from East Shoa Zone (Adami Tulu JidoKombolcha $(\mathrm{A} / \mathrm{T} / \mathrm{J} / \mathrm{K})$ and Dugda districts) which are adjacent to Lake Ziway were selected purposively on the basis of their accessibility and for the fact that $70 \%$ of the fishers residing around the lake are found in these districts [3]. In the next stage, two kebeles (Peasant Association, PAs) from each district were also selected purposively. In the final stage, simple random sampling was employed to select 120 sample household units from each of the respective kebeles (PAs) with whom the survey questionnaire has been administered. Since the number of fishermen households in each kebele was very small as compared to the size of the non-fisher households, the total sample size was divided equally between fishers and non-fishers respectively. And the sample proportion of fishermen and non-fishermen in each kebele was determined proportionally.

Data Analysis: Data obtained from questionnaire were summarized, edited and coded. The data was entered in to the SPSS spreadsheet and cleaned for irregularities. Descriptive statistical analysis has also been used. The independent variables were defined and the binary logistic regression model was used to analyze factors determining household engagement in fishing (Binary variables).The existence of multi-collinearity, a situation where it becomes difficult to disentangle the separate effects of independent variables on the dependent variable because of strong relationships among them [9], was checked using the methods of variance inflation factor for continuous variables and contingency coefficients for discrete ones. 


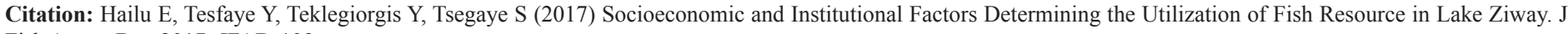
Fish Aquac Dev 2017: JFAD-109.

\section{Results and Discussions}

Of the total sample respondents interviewed there were no female households selected which might be because of the fact that fishing activity, especially harvesting from the lake, is culturally a male responsibility. Therefore, all sample households were male households.

\section{Socioeconomic Characteristics}

\section{Distribution by the Age of the Household Head}

The difference in average ages between sample fishermen and non-fishermen is statistically significant $(\mathrm{P}<0.01)$. The result in (Table1) indicates that sample fishermen household heads are relatively younger in age than those who are non-fishermen.

\begin{tabular}{|c|c|c|c|c|c|c|}
\hline \multirow{2}{*}{ Age Group } & \multicolumn{2}{|c|}{ Non-Fishermen } & \multicolumn{2}{|c|}{ Fishermen } & \multicolumn{2}{|c|}{ Total } \\
\hline & Number & $\%$ & Number & $\%$ & Number & $\%$ \\
\hline $15-25$ & 2 & $3 \%$ & 3 & $5 \%$ & 5 & $4 \%$ \\
\hline $26-45$ & 45 & $75 \%$ & 29 & $48 \%$ & 74 & $62 \%$ \\
\hline $46-55$ & 9 & $15 \%$ & 15 & $25 \%$ & 24 & $20 \%$ \\
\hline$>=55$ & 4 & $7 \%$ & 13 & $22 \%$ & 17 & $14 \%$ \\
\hline Total & 60 & $100 \%$ & 60 & $100 \%$ & 120 & $100 \%$ \\
\hline Mean & \multicolumn{2}{|c|}{43.6} & \multicolumn{2}{|c|}{38.33} & & \\
\hline Standard deviation & \multicolumn{2}{|c|}{11.04} & \multicolumn{2}{|c|}{9.52} & & \\
\hline T-square & \multicolumn{4}{|c|}{2.799 (Significant at 1\%) } & & \\
\hline
\end{tabular}

Table 1: Distribution of Sample Households by Age Group.

\section{Distribution by Educational Level of the Household Head}

As indicated in (Table 3), the chi-square test statistic shows literacy status is significant between fishermen and non-fishermen households $(\mathrm{P}<0.05)$.

\begin{tabular}{|c|c|c|c|c|c|c|}
\hline \multirow{2}{*}{ Education } & \multicolumn{2}{|c|}{ Non-fisherman } & \multicolumn{2}{|c|}{ Fisherman } & \multicolumn{2}{|c|}{ Total } \\
\hline & Number & $\%$ & Number & $\%$ & Number & $\%$ \\
\hline Illiterate & 8 & $13 \%$ & 4 & $7 \%$ & 12 & $10 \%$ \\
\hline Read and Write & 10 & $17 \%$ & 22 & $37 \%$ & 32 & $27 \%$ \\
\hline $1^{\text {st }}$ cycle primary school $(1-4)$ & 13 & $22 \%$ & 14 & $23 \%$ & 27 & $23 \%$ \\
\hline $2^{\text {nd }}$ cycle primary school $(5-8)$ & 14 & $23 \%$ & 10 & $17 \%$ & 24 & $20 \%$ \\
\hline High School (9-12) & 5 & $8 \%$ & 8 & $13 \%$ & 13 & $11 \%$ \\
\hline Above High School & 10 & $17 \%$ & 2 & $3 \%$ & 12 & $10 \%$ \\
\hline Total & 60 & & 60 & & 120 & \\
\hline \multicolumn{7}{|l|}{ Chi-square } \\
\hline Illiterate & 8 & $13 \%$ & 4 & $7 \%$ & 12 & $10 \%$ \\
\hline Literate & 52 & $87 \%$ & 56 & $93 \%$ & 108 & $90 \%$ \\
\hline Total & 60 & & 60 & & 120 & \\
\hline
\end{tabular}

Table 3: Distribution of Sample Households by Educational Level of the Household Head.

\section{Distribution by Farm Land Holding Size}

The result in (Table 4) reveals that the difference in means of the size of farm landowned by the two groups of sample households is significant at $10 \%$ level. The average farm land size of fishermen being 0.69 ha and that of non-fishermen is 1.04 ha shows that engagement in fishing activity of households holding larger size of farm land is less than those who own relatively small size or no farm land

\begin{tabular}{|c|c|c|c|c|c|c|}
\hline \multirow{2}{*}{$\begin{array}{l}\text { Farm land Hold- } \\
\text { ing size in Km }\end{array}$} & \multicolumn{2}{|c|}{ Non-Fishermen } & \multicolumn{2}{|c|}{ Fishermen } & \multicolumn{2}{|c|}{ Total } \\
\hline & Number & $\%$ & Number & $\%$ & Number & $\%$ \\
\hline$<=0.5$ & 25 & $42 \%$ & 30 & $51 \%$ & 55 & $46 \%$ \\
\hline
\end{tabular}




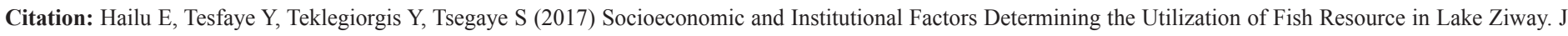
Fish Aquac Dev 2017: JFAD-109.

\begin{tabular}{|c|c|c|c|c|c|c|}
\hline $0.51-1.0$ & 23 & $38 \%$ & 18 & $31 \%$ & 41 & $34 \%$ \\
\hline $1.01-2.0$ & 11 & $18 \%$ & 11 & $19 \%$ & 22 & $18 \%$ \\
\hline$>2$ & 1 & $2 \%$ & 0 & $0 \%$ & 1 & $1 \%$ \\
\hline Total & 60 & $100 \%$ & 59 & $100 \%$ & 119 & $100 \%$ \\
\hline Mean & \multicolumn{2}{|c|}{1.04} & \multicolumn{2}{|c|}{0.69} & & \\
\hline Standard deviation & \multicolumn{2}{|c|}{1.94} & \multicolumn{2}{|c|}{0.69} & & \\
\hline T-Value & \multicolumn{5}{|c|}{1.287 (Significant at $10 \%$ ) } & \\
\hline
\end{tabular}

Table 4: Distribution of Households by Farm Land Holding Size.

\section{Distribution by Livestock Holding}

The types of livestock considered were cattle, sheep, goats, equine, chicken and honeybees. In order to help the standardization of the analysis, the livestock number was converted to Tropical Livestock Unit (TLU). The conversion factor used was based on Jahnke,et al.[10]. As shown in (Table 5) the average in TLU of livestock holding is 2.03 and 2.83 for fishermen and non-fishermen respectively, where the difference in the average livestock holding of fishermen and non-fishermen households is statistically significant at $5 \%$. This implies that households with a large number of livestock are not engaged in fishing as compared to those who are own small number of livestock.

\begin{tabular}{|c|c|c|c|c|c|c|}
\hline \multirow{2}{*}{$\begin{array}{l}\text { Live stock hold- } \\
\text { ing } \\
\text { in TLU } \\
\end{array}$} & \multicolumn{2}{|c|}{ Non-Fishermen } & \multicolumn{2}{|c|}{ Fishermen } & \multicolumn{2}{|c|}{ Total } \\
\hline & Number & $\%$ & Number & $\%$ & Number & $\%$ \\
\hline$<=0.5$ & 15 & $25 \%$ & 20 & $33 \%$ & 35 & $29 \%$ \\
\hline $0.51-2$ & 11 & $18 \%$ & 12 & $20 \%$ & 23 & $19 \%$ \\
\hline $2.01-4.0$ & 20 & $33 \%$ & 19 & $32 \%$ & 39 & $33 \%$ \\
\hline$>4$ & 14 & $23 \%$ & 9 & $15 \%$ & 23 & $19 \%$ \\
\hline Total & 60 & $100 \%$ & 60 & $100 \%$ & 120 & $100 \%$ \\
\hline Mean & \multicolumn{2}{|c|}{2.83} & \multicolumn{2}{|c|}{2.03} & & \\
\hline Standard deviation & \multicolumn{2}{|c|}{3.08} & \multicolumn{2}{|c|}{2.07} & & \\
\hline T-value & \multicolumn{6}{|c|}{1.67 (Significant at $5 \%$ ) } \\
\hline
\end{tabular}

Table 5: Distribution of households by Livestock holding.

\section{Distribution by Other Income Generating Activities (OIGA)}

The result shown in (Table 6) reveals that at $1 \%$ level there is a significant difference in proportion of fishermen engaged in nonfarm income generating activities. The result clearly indicates that those households with no other income generating activities are engaged in fishing more than those involved in other income generating activities. It can also be observed from the result that the main sources of income for the non-fisher households with other income generating activities are labour sale (34.2\%), government employment (31.6), pity trade (21.1\%) and hand crafting (7.9\%). This implies the fact that most of them earn their income by working in different farming enterprises as daily labourers, like the floriculture and horticulture enterprises situated in the area, and some of them are working in different governmental organizations. Only those households which are small in number are doing pity trades and hand crafting as a source of income for their livelihood.

\begin{tabular}{|c|c|c|c|c|c|c|}
\hline \multirow{2}{*}{ OIGA } & \multicolumn{2}{|c|}{ Non-fishermen } & \multicolumn{2}{|c|}{ Fishermen } & \multicolumn{2}{|c|}{ Total } \\
\hline & Number & $\%$ & Number & $\%$ & Number & $\%$ \\
\hline Labor sale & 13 & $34.20 \%$ & 3 & $30 \%$ & 16 & 33.3 \\
\hline Pity trade & 8 & $21.10 \%$ & 7 & $70 \%$ & 15 & 31.2 \\
\hline Help from relatives & 2 & $5.20 \%$ & 0 & 0 & 2 & 4.2 \\
\hline Hand craft & 3 & $7.90 \%$ & 0 & 0 & 3 & 6.25 \\
\hline Government employment & 12 & $31.60 \%$ & 0 & 0 & 12 & 25 \\
\hline
\end{tabular}




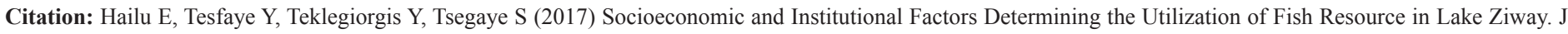
Fish Aquac Dev 2017: JFAD-109.

\begin{tabular}{|c|c|c|c|c|c|c|}
\hline Total & 38 & & 10 & & 48 & \\
\hline OIGA Not available & 22 & $37 \%$ & 50 & $83 \%$ & 72 & $60 \%$ \\
\hline OIGA Available & 38 & $63 \%$ & 10 & $17 \%$ & 48 & $40 \%$ \\
\hline Total & 60 & $100 \%$ & 60 & $100 \%$ & 120 & $100 \%$ \\
\hline Chi- Square & \multicolumn{5}{|l|}{27.22 (Significant at $1 \%$ ) } \\
\hline
\end{tabular}

Table 6: Summary of Households by Their Involvement in Other Income Generating Activities.

\section{Institutional Factors}

\section{Distribution of Sample Households by Access to Credit}

(Table 7) shows that the proportion of households involved in fishing activity is associated with access to credit at less than $1 \%$ level of significance. Comparing the proportion of the fisher men who had access to credit (38\%) with the proportion of non-fishermen who had access to credit (15\%), leads us to generalize the fact that households with a better access to credit were more liable to be engaged in fishing activity as compared to those with less access to credit.

\begin{tabular}{|c|c|c|c|c|c|c|}
\hline \multirow{2}{*}{ Credit Access } & \multicolumn{2}{|c|}{ Non-Fisherman } & \multicolumn{2}{c|}{ Fisherman } & \multicolumn{2}{c|}{ Total } \\
\cline { 2 - 7 } & Number & $\%$ & Number & 37 & $62 \%$ & 88 \\
\hline No Access & 51 & $85 \%$ & 23 & $38 \%$ & 32 \\
\hline Have Access & 9 & $15 \%$ & 60 & $100 \%$ & 120 \\
\hline Total & 60 & $100 \%$ & 8.352 (Significant at $1 \%$ ) \\
\hline Chi-square & \multicolumn{7}{|c}{} \\
\hline
\end{tabular}

Table 7: Distribution by Access to Credit.

\section{Distribution by the Distance between the Lake and the Home of the Household}

The average distance from the lake of sample fishermen households is $2.033 \mathrm{~km}$ while it is $3.97 \mathrm{~km}$ for non-fishermen and the difference is significant at a less than $1 \%$ probability level (Table 8). One can also observe from the result that $93 \%$ of the fishermen and $48 \%$ of the non-fishermen are living at a distance of less than $3.5 \mathrm{kms}$ from the lake. Therefore, we can generalize the fact that the nearer household residents live to the lake, the more liable they become to be involved in fishing activity than those living far away.

\begin{tabular}{|c|c|c|c|c|c|c|}
\hline \multirow{2}{*}{$\begin{array}{c}\text { Distance from } \\
\text { households' } \\
\text { home of the lake }\end{array}$} & \multicolumn{2}{|c|}{ Non-Fishermen } & \multicolumn{2}{|c|}{ Fishermen } & \multicolumn{2}{|c|}{ Total } \\
\hline & Number & $\%$ & Number & Number & $\%$ & Number \\
\hline$<=1.5$ & 6 & $10 \%$ & 30 & $50 \%$ & 36 & $30 \%$ \\
\hline $1.51-3.5$ & 23 & $38 \%$ & 26 & $43 \%$ & 49 & $41 \%$ \\
\hline $3.51-5$ & 20 & $33 \%$ & 2 & $3 \%$ & 22 & $18 \%$ \\
\hline $5.01-8$ & 9 & $15 \%$ & 1 & $2 \%$ & 10 & $8 \%$ \\
\hline$>8$ & 2 & $3 \%$ & 1 & $2 \%$ & 3 & $3 \%$ \\
\hline Total & 60 & $100 \%$ & 60 & $100 \%$ & 120 & $100 \%$ \\
\hline Mean & \multicolumn{2}{|c|}{3.97} & \multicolumn{2}{|c|}{2.033} & & \\
\hline Standard deviation & \multicolumn{2}{|c|}{2.09} & \multicolumn{2}{|c|}{2.04} & & \\
\hline T-value & \multicolumn{6}{|c|}{-5.126 (Significant at $1 \%$ ) } \\
\hline
\end{tabular}

Table 8: Distribution of Households by the Distance from the Lake of their Home.

It was observed from the summary of the fishermen sample households included in the data, 34(57\%) are members of fishermen cooperatives and $26(43 \%)$ are not. This category of fishermen has been used to compare such institutional aspects as market accessibility, perception on the enforcement of fishing regulations and training accessibility between those who are members of fishermen cooperatives and those who are not. 


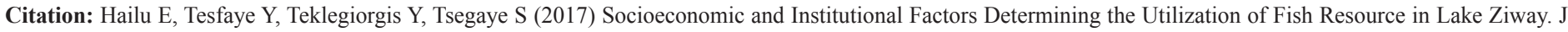
Fish Aquac Dev 2017: JFAD-109.

\section{Distribution by Market Accessibility}

Market accessibility is referred to as availability of demand for fish products on regular basis at the local market or at the landing sites. The result in (Table-9) shows that the proportion of fishermen being a member of fishermen cooperatives is independent of market access ( $p>0.1$ ). It's been found from the analysis that $91 \%$ of cooperative members and $96 \%$ of non-members have access to market and it indicates that both groups of fishermen have similar perception on the accessibility of the market.

\begin{tabular}{|c|c|c|c|c|c|c|}
\hline \multirow{2}{*}{ Market Accessibility } & \multicolumn{4}{|c|}{ Cooperative Member } & \multicolumn{2}{|c|}{ Total } \\
\hline & No & $\%$ & Yes & $\%$ & Number & $\%$ \\
\hline Have No Market Access & 1 & $4 \%$ & 3 & $9 \%$ & 4 & $7 \%$ \\
\hline Have Market Access & 25 & $96 \%$ & 31 & $91 \%$ & 56 & $93 \%$ \\
\hline Total & 26 & $100 \%$ & 34 & $100 \%$ & 60 & $100 \%$ \\
\hline Chi-Square & \multicolumn{6}{|c|}{0.587} \\
\hline
\end{tabular}

Table 9: Distribution by Market Access of Fishermen.

\section{Distribution by Perception on the Level of Enforcement of the Fishing Rules}

As we can see from (Table 10), $83 \%$ of the sample households perceive the effort in enforcing the regulations by the authorized body to be low where it was $86 \%$ and $79 \%$ for those who are member of fishermen cooperatives and those who are not, respectively. The result also indicates that there is no significant difference between the two groups of fishermen in their perception regarding the enforcement of fishing regulations $(\mathrm{p}>0.1)$.

\begin{tabular}{|c|c|c|c|c|c|c|c|}
\hline \multirow{2}{*}{$\begin{array}{l}\text { Perception on } \\
\text { the Level of } \\
\text { Enforcement } \\
\text { of the Fishing } \\
\text { Regulations }\end{array}$} & \multicolumn{7}{|c|}{ Cooperative Member } \\
\hline & No & $\%$ & Yes & $\%$ & Chi-Square & Total & \\
\hline Not at all & 4 & $17 \%$ & 3 & $11 \%$ & \multirow{5}{*}{0.419} & 7 & $13 \%$ \\
\hline Low & 19 & $79 \%$ & 24 & $86 \%$ & & 43 & $83 \%$ \\
\hline Medium & 1 & $4 \%$ & 1 & $4 \%$ & & 2 & $4 \%$ \\
\hline high & 0 & $0 \%$ & 0 & $0 \%$ & & 0 & $0 \%$ \\
\hline Total & 24 & $100 \%$ & 28 & $100 \%$ & & 52 & $100 \%$ \\
\hline
\end{tabular}

Table 10: Distribution by Perception on the Level of Enforcement the Fishing Regulations.

\section{Distribution by the Training Accessibility}

There is no significant difference in proportion between members and non-member fishermen cooperatives with regard to access to training on fishery resource utilization $(\mathrm{p}>0.05)$. The result from (Table 11) shows the proportion of those fishermen who are members of cooperatives received training is $38 \%$ and for those who are not members is $19 \%$. The proportion of those who had no access to training is $62 \%$ and $81 \%$ for members and nonmembers of fishermen cooperatives respectively. This implies that being not a member of cooperatives is in no difference to being a member with regard to access to training.

\begin{tabular}{|c|c|c|c|c|c|c|}
\hline \multirow{2}{*}{ Training } & \multicolumn{3}{|c|}{ Cooperative Member } & \multicolumn{2}{c|}{ Total } \\
\cline { 2 - 6 } & No & $\%$ & Yes & $62 \%$ & 42 \\
\hline Have No Access & 21 & $81 \%$ & 21 & $38 \%$ & $70 \%$ & 18 \\
\hline Have Access & 5 & $19 \%$ & 34 & $100 \%$ & 60 & $100 \%$ \\
\hline Total & 26 & $100 \%$ & \multicolumn{2}{|c|}{2.534} \\
\hline Chi- Square & \multicolumn{7}{|c|}{} \\
\hline
\end{tabular}

Table 11: Distribution by Access to Training.

\section{Distribution by the Household's Reason to be Engaged in Fishing}

As we can see the results in (Table 12), the highest proportions of the respondents were motivated to be involved in fishing due to lack of other source of income and because it is a family business indicating the importance of having alternative source of income 


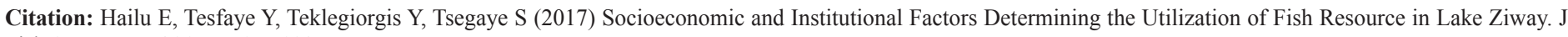
Fish Aquac Dev 2017: JFAD-109.

generating activities for the households residing around the lake along with establishment of strong institutional arrangement in enforcing regulations of the utilization of fish resources so that harvesting the resource in laissez-faire manner to become hardly easy.

\begin{tabular}{|c|c|c|c|c|c|c|}
\hline \multirow{3}{*}{$\begin{array}{l}\text { Driving Reasons as Factors } \\
\text { Easy access of the resource }\end{array}$} & \multicolumn{4}{|c|}{ Cooperative Member } & \multirow{2}{*}{\multicolumn{2}{|c|}{ Total }} \\
\hline & No & $\%$ & Yes & $\%$ & & \\
\hline & 18 & $16 \%$ & 25 & $16 \%$ & 43 & $16 \%$ \\
\hline Lack of other source of income & 21 & $18 \%$ & 28 & $18 \%$ & 49 & $18 \%$ \\
\hline Shorter time of earning fish income & 16 & $14 \%$ & 29 & $19 \%$ & 45 & $17 \%$ \\
\hline Easy means of income generating & 21 & $18 \%$ & 21 & $14 \%$ & 42 & $16 \%$ \\
\hline Easily available fish market & 20 & $18 \%$ & 19 & $12 \%$ & 39 & $14 \%$ \\
\hline Family business & 18 & $16 \%$ & 32 & $21 \%$ & 50 & $19 \%$ \\
\hline Total & 114 & $100 \%$ & 154 & $100 \%$ & 268 & $100 \%$ \\
\hline $\mathrm{n}=268$ due to multiple responses & & & & & & \\
\hline
\end{tabular}

Table 12: Distribution by Driving Reasons to get involved in Fishing.

\section{Econometric Results and Discussion of Factors Influencing Fish Resource Utilization}

Test of multi-collinearity reveals no threat of multi-collinearity among the continuous variables. Regarding the discrete variables, only between the variables Marital Status and Educational status was multi-collinearity problem observed. Therefore, the variable Marital Status was dropped from the analysis and the regression was done using the remaining eight variables.

\section{Goodness of Fit for the Model}

(Table 13) Indicates Hosmer and Lemeshow test of goodness of fit with the p value of 0.770 . Since P- value is greater than 0.05 it indicates that there is no evidence for the model not to fit and it is considered to be desirable [11]. Nagelkerke coefficient of determination (R2) measures was 0.613 implying that about $61.3 \%$ of the variation in the dependant variable were explained by independent variables included in the model. In order to determine the explanatory variables that are good predictors of fish resource utilization in the lake, the logit regression model was estimated using the Maximum Likelihood estimation method. The results of the analysis are presented in Table 20. Looking at the results of the regression model it has correctly predicted 84 percent of the sample households. The correctly predicted fishermen and the correctly predicted on-fishermen of the logit model are 83.1 percent and 85 percent respectively. Thus, the model predicts both groups correctly.

\begin{tabular}{|c|c|c|c|c|c|c|}
\hline Variable & Esti.Coeff. $(\beta)$ & S. E. & Wald & d.f & Sig. & $\mathrm{OR}\left(\mathrm{e}^{\beta}\right)$ \\
\hline Age & -0.072 & 0.033 & 4.823 & 1 & $.028^{*}$ & 0.931 \\
\hline $\mathrm{FaSz}$ & 0.29 & 0.15 & 3.74 & 1 & 0.053 & 1.336 \\
\hline educ & & & 14.211 & 5 & $.014^{*}$ & \\
\hline $\operatorname{Educ}(1)=$ illiterate & 1.763 & 1.222 & 2.084 & 1 & 0.149 & 5.833 \\
\hline $\operatorname{Educ}(2)=$ Read and write & 3.351 & 1.08 & 9.631 & 1 & $.002^{* *}$ & 28.544 \\
\hline $\operatorname{Educ}(3)=1{ }^{\text {st }}$ cycle elementary education & 2.1 & 1.118 & 3.528 & 1 & 0.06 & 8.169 \\
\hline $\operatorname{Educ}(4)=2^{\text {nd }}$ cycle elementary education & 0.495 & 1.058 & 0.219 & 1 & 0.64 & 1.641 \\
\hline Educ(5)=high school education & 1.203 & 1.187 & 1.027 & 1 & 0.311 & 3.331 \\
\hline DHL & -0.399 & 0.164 & 5.889 & 1 & $.015^{*}$ & 0.671 \\
\hline FaLHS & -0.171 & 0.251 & 0.46 & 1 & 0.497 & 0.843 \\
\hline LSH & -0.19 & 0.109 & 3.017 & 1 & 0.082 & 0.827 \\
\hline OIGA (1) & -1.795 & 0.594 & 9.141 & 1 & $.003^{* *}$ & 0.166 \\
\hline CrAc (1) & 2.073 & 0.83 & 6.238 & 1 & $.013^{*}$ & 7.945 \\
\hline Constant & 1.843 & 1.349 & 1.868 & 1 & 0.172 & 6.318 \\
\hline
\end{tabular}

Table 13: Logistic Regression Results. 


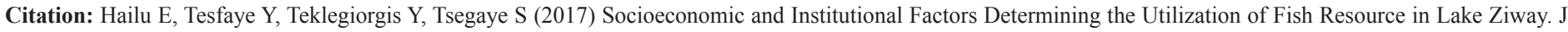
Fish Aquac Dev 2017: JFAD-109.

\section{Explanation of the Significant Variables Influencing Fish Resource Utilization}

Based on the model results age, Educational level, Distance from home of the lake, other income generating activities and Access to credit were significant variables at less than $5 \%$ probability level.

\section{Age of the House Hold (Age)}

This variable was found to significantly influence the engagement of a household in fishing activity. The coefficient of the variable being significant at $5 \%$ level of significance with a negative sign implies the fact that older aged households are less likely to engage in fishing activity which is in line with the priori assumption. The odds ratio of engagement in fishing activities indicates that as the age of the household increases by a year, this engagement in fishing activity declines by a factor of 1.074 (i.e. $1 / 0.931)$. The result is consistent with the study conducted by Tadesse [12] on Lake Tana.

\section{Educational Level (Educ)}

Looking at the results for educational level, there is a highly significant overall effect (sig=0.014) in determining household's engagement in fishing activity at $5 \%$ level of significance. Moreover, Educ (2) is significantly different from a higher education (Above high school), our reference variable, (at 1\%) of a household in becoming a fisherman. The odds ratio value tells us that those whose level of education is reading and writing are 28.5 times more likely to be engaged in fishing activity than those with a higher educational level in their involvement of fishing activity. Educ (3) is significantly different from a higher education (at $10 \%$ ) in the engagement of fishing activity. And the odds ratio also tells us that households with an 1st cycle primary school (1-4) are 8.17 times more likely to be involved in fishing activity than those above high school educational level. The rest of design variables of educational level are not significantly different from a higher educational level. So, the more households are educated, the less likely they are to become involved in fishing activities.

\section{Distance of Households' Home from the Lake (DHL)}

Distance of the household's living home from the lake was found to significantly determine the engagement in fishing activity of the household. Similar to the preset hypothesis, the coefficient of the variable with a negative sign indicates that households living far away from the lake are less likely to be involved in fishing activity. The odds ratio signifies that as the distance increases by one KM the engagement in fishing activity of the household declines by a factor of 1.499 , i.e., 1/0.671). Alternatively, it means households living nearer to the lake are $33 \%$ (i.e., $(1-0.671) * 100$ ) more likely to be engaged in fishing activity than those living farther from the lake. The result is consistent with the study conducted by Tadesse [12] on Lake Tana.

\section{Other Income Generating Activities (OIGA)}

This variable was found to be highly significant at $1 \%$ level of significance and had a negative association with fish resource utilization. The odds ratio indicates that engagement in fishing activity declines by a factor of 6.02 (i.e., 1/0.166) for those households who are involved in other income generating activities. That is, those with no OIGA are $83.4 \%$ more likely to be involved in utilization of fish resource. Therefore, availability of other opportunities to earn income for their livelihood reduces the chance for a household to engage in fishing activity. The result is consistent with the study conducted by Heavensophy [13] on coastal villages of Babagamoyo district of Tanzania which argues the fact that lack of alternative source of income induces people to venture into fishing with a possible reason that fishing is the income generating activity that can easily be accessed in coastal area; it was also consistent with the results from a study performed in Chenab River near Muzafargarh district of Pakistan [14] and with the result from the study in the central region of Ghana [15].

\section{Credit Access (CrAc)}

Credit access was found to significantly and positively determine the household's engagement in fishing activity at 5\% level of significance which implies that the probability of a household 's involvement in fishing activity increases as the household gets access to credit. This agrees with the previous hypothesis set that households with credit access are more likely to be involved in fishing activity. The odds ratio shows us that those who have access to credit were 7.95 times more likely to be involved in fishing activity than those who didn't take credit. The reason here is that fishermen households who take credits spent the money for purchasing fishing equipments and for running the fishing activity. The result is consistent with the study conducted by Acquah \& Abunyuwah [15] of Ghana. It is also consistent with the results of Tadesse [12] and the result of the study around Lake Malombe of Malawi [16]. The result also agrees with the study by [14] of Pakistan. But it contrasts with that of Heavensophy [13] which declares as credit access to have a negative impact on fishery resource utilization. The final model, then, becomes:

$\mathrm{g}(\mathrm{x})=1.843-0.072$ Age $+1.763 \mathrm{Educ}(1)+3.351 \mathrm{Educ}(2)+2.1 \mathrm{Educ}(3)+$ 0.495Educ(4)+1.203Educ(5)-0.399DHL-1.795OIGA+2.073CrAc

\section{Sensitivity Analysis}

The relative importance of the significant variables included in the model was computed by observing the probability changes where the probability was calculated by keeping the continuous variables at their mean value and the dummy variables at their modal (most frequent values $(0,1)$. "An average household" is defined in order to rank the relative impact of the explanatory variables in terms of their relative effect. The average house hold was with an average age of 41 and living $2.99 \mathrm{k} . \mathrm{m}$ away from the lake. 


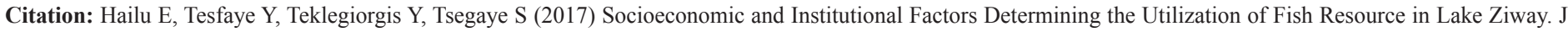
Fish Aquac Dev 2017: JFAD-109.

He was with a literacy level of reading and writing (27\%) and had no access to credit (75\%). The log odd of being fisherman for an average house hold was found to be 0.74 and the probability of involvement in fishing activity for an average household was 0.68.

The results from the predicted probabilities of significant continuous variables indicated that a lyear increase in the age of an average household (average in the rest of all aspects) will decrease the probability of his engagement in fishing activities by $1.6 \%$; and a $1 \mathrm{~km}$ increase in the distance of the residence from the lake of an average household would decrease the probability of fishery resource utilization by $8.7 \%$; and the results for the dummy independent variables indicated that the probability of being fisherman increases for an average household with an educational level of reading and writing by $30.4 \%$ as compared to a household with a higher level (college) of education. Furthermore, the probability for a household who is average in all aspects and does not have other source of income increases by $42 \%$ and the probability for the one who has access to credit increases by $26 \%$.

\section{Conclusions and Recommendations}

In this study factors that determine the utilization of fish resource in Lake Ziway have been investigated and those that revealed to have a negative impact on household's engagement in fishing activity are age, distance of the household's home from the lake, other income generating activities and educational level where as credit access was found to have a positive impact on fish resource utilization. This, with the poorest level of enforcing the fishing regulations on the lake, brings the people with an opportunity to participate in fishing activities as an easy income generating business. The proportion of households with credit access is more than a double higher for fisher men than non-fisher men leaving the factor with a positive association of fish resource utilization. Therefore, reducing the overutilization of fish resource in the lake demands an effort to address these factors seriously. The proclamation for fishery management already at hand is not given the necessary attention by the governmental bodies as done for other livestock and crop production sectors. On the other hand, the agricultural office of the districts under this study complain the shortage of experts in the area of fishery as a main reason for the poor implementation of the regulations, and hence for the fishery resource management to freeze. It was discussed during focus group discussion that a collective management (as co-management system) was tried to be applied on the lake by forming committees comprised of fishermen, non-fishermen and members from governmental agriculture office. But it failed in achieving its goal due to different reasons, the main one of which is the strong social integration among the local people hindering the committee to deal with those illegal fishers who are the members of the society there by preventing it from active engagement in managing the utilization of the resource as required. The other reason was lack of continuous monitoring on the activities of the committee and absence of support on the gaps the committee is facing in effecting the system properly. Hence, the need to strengthen the co-management system is critically important in order to address the problems associated with the utilization of fish resource in the lake. Improving the educational level of households living around the lake and facilitating diversified income generating opportunities for the households living around the lake is also necessary in dealing with the situation. Likewise, the credit program should consider unemployed youth; creating favorable conditions, especially in terms of production and better market access, for those who own agricultural land and livestock as well as offering the necessary support for the fishermen cooperatives should also be done.

\section{Acknowledgements}

The authors would like to thank Wondo Genet Forestry and Natural Resource College, especially the School of Graduate Studies, Alage agricultural TVET College, Dugdaworeda and Adami Tulu JidoKombolchaworeda agricultural offices and Ziway fisheries research centre for their support.

\section{References}

1. World Bank (2015) Economic Review.

2. Sileshi A (2013) Managing water for livestock and fisheries development. The Monthly Publication from the Ethiopian Embassy in London Ethiopian News.

3. Endebu M, Lema A, Genet T, Mitike A, Regassa B, et al. (2013) Fisheries base line survey report of Lake Zeway, Community based fisheries management to the local communities of Lake Zeway.

4. Hengsdijk H, Jansen $\mathrm{H}$ (2006) Agricultural development in the Central Ethiopian Rift valley: A desk-study on water-related issues and knowledge to support a policy dialogue: 1-32.

5. Dawit G, Asefa A, Gezahegn A, Fekadu B (2014) Analysis of the Impact of Fishery Cooperatives on Fishing Activity of Rural Households Around Lake Ziway and Lagano in Ethiopia'Middle-East Journal of Scientific Research.

6. Endebu M, Lema A, Genet T, Mitike A, Regassa B, et al. (2015) Fisheries Baseline Survey Describing Status of Fisheries in Lake Zeway, Ethiopia. J Fisheries Livest Prod 3:129.

7. Elias D, Daba T (2009) Some aspects of reproductive biology of the crucian carp, Carassius carassius (L., 1758) (Pisces: Cyprinidae) in lake ziway, Ethiopia. Ethiopia J Biol Sci 8: 109-121.

8. Green SB (1991) How Many Subjects Does It Take To Do A Regression Analysis? Multivariate Behavioral Research26: 499-510.

9. Maddala G (1997) Limited Dependent and Qualitative Variables in Econometrics. Economic Society Monography3: 456.

10. Jahnke H, Tacher G, Keil P, Rojat D (1988) Livestock production in tropical Africa with special reference to the tse-tse affarent zone, FAO

11. Hosmer D, Lemshow S (2000) Applied logistic regression. In:2. Wiley Seriu in Probability and Stlltisrics, A Wiley-Interscience Publication.

12. Tadesse B (2007) Analysis of factors determining potential fish resource utilization in lake tana. An MSc. thesis, College of Agriculture, Haramaya University, Department of Agricultural Economics, School of Graduate Studies, Ethiopia. 
Citation: Hailu E, Tesfaye Y, Teklegiorgis Y, Tsegaye S (2017) Socioeconomic and Institutional Factors Determining the Utilization of Fish Resource in Lake Ziway. J Fish Aquac Dev 2017: JFAD-109.

13. Mfinanga $\mathrm{H}$ (2014) Analysis Of Economic Determinants For Households Nvolvement In Fishing For Livelihoods In Coastal Villages Of Bagamoyo District, Tanznia. A Dissertation, For The Degree Of Master Of Science In Environmental And Natural Resource Economics Of Sokoine University Of Agriculture., Morogoro: 1-79.

14. Faridi M, Gillani D (2012) Socio-economic Factors Influencing People to Become Fisherman around Chenab River near District Muzafargarh 2: 9.
15. Acquah D, Abunyuwah I (2011) Logit Analysis Of Socio-Economic Factors Influencing People To Become Fishermen In The Central Region Of Ghana. Journal Of Agricultural Sciences 56: 55-64.

16. Matiya G, Wakabayashi Y, Ng'on D, Takenouchi N (2005) A Logit Analysis of Socio-economic Factors Influencing People to Become Fisherman Around Lake Malombe in Malawi. Journal of Applied Sciences Research 1:18-23. 